\title{
Arthrobacter (ROA) ve Kadife Çiçeği (Tagetes patula) Ekstraktlarının Meloidogyne incognita (Kofoid\&White) Populasyonuna Karşı Etkinliği
}

\author{
Ramazan ÇETINTAŞ ${ }^{1 *}$, Hilmi KARA ${ }^{2}$
}

${ }^{1}$ KSÜ, Ziraat Fakültesi, Bitki Koruma Bölümü, Kahramanmaraş

${ }^{2}$ YYÜ, Ziraat Fakültesi, Bitki Koruma Bölümü, Van

Geliş (Received) : 01.04.2016

Kabul (Accepted): 14.04.2016

\begin{abstract}
ÖZET: Nematodlar ile mücadelede yoğun olarak kullanılan nematisitlerin çevreye ve insan sağlığına verdiği zararlardan dolayı, son yıllarda bu patojenlere karşı mücadelede yeni alternatif yöntemler son yıllarda daha sıkça aranmaya başlanmıştır. Bu çalışmada da, serada yetiştirilen domates ve hıyar bitkileri üzerinde, arthrobacter (ROA) ve kadife çiçeği (Tagetes patula) bitki ekstraktının Meloidogyne incognita'nın üç ayrı seviyesi (0 J2/bitki,1000 J2/bitki ve2000 J2/bitki)'ne karşı etkinliği araştırılmıştır. Çalışmada Devguard (Iprodione) kontrol amaçlı kullanılmıştır. Kontrol muamelelerindeki bitkilerde bitki yaş ağırlıklarının diğer Tagetes patula ve arthrobacter (ROA) muamelelerine göre daha yüksek olduğu görülmüştür $(P<0.05)$. Tagetes patulave arthrobacter (ROA) uygulamalarının farklı nematod inokulum seviyelerindeki veri sonuçları istatistiki olarak farklılıklar göstermiştir $(P<0.05)$. Elde edilen sonuçlar doğrultusunda bu iki etmenin hem etkili hem de doğal ve düşük maliyetli olması nedeniyle Meloidogyne incognita ile mücadelede özellikle sera yetiştiriciliğinde kullanılabileceği belirlenmiștir.
\end{abstract}

Anahtar Kelimeler: Domates, Hıyar, Kök-ur Nematodu, Arthrobacter, Tagetes patula

\section{The effects of Arthrobacter (ROA) and Marrygold (Tagetes patula) Plant Extracts Against Meloidogyne incognita (Kofoid \& White) Populations}

\begin{abstract}
Due to the detrimental effect of nematicides to the environment and to human health, new alternative control methods for nematodes are more often being investigated in recent years. In this study, the nematicidial effects of Arthrobacter (ROA) and marigold (Tagetes patula) plant extracts as compared Parodine (Devguard) on three inoculum level of Meloidogyne incognita root-knot nematode (0 J2/plant, 1000J2/plant, 2000J2/plant) were investigated on greenhouse grown tomatoes and cucumber. Average plant fresh weight of control Iprodione was significantly higher than those of Tagetes patula and Arthrobacter $(\mathrm{ROA})(P<0.05)$. Statistical analysis of data taken from Tagetes patula and Arthrobacter (ROA) treatments were varied among nematode inoculum levels $(P<0.05)$. Based on the results of this study, it suggested that because of their effectiveness, low cost and natural structure, these two substances could be good alternatives in Meloidogyne incognita control tactics, particularly, in green house crop production.
\end{abstract}

Key Words: Tomatoes, Cucumber, root-knot nematode, Arthrobacter, Tagetes patula

\section{GİRIŞ}

Kök-ur nematodları iki binden fazla bitki türünde zararlı olan ve yüksek verim kayıplarına neden olan özelikle bahçe bitkileri ve ormancılı̆̆ 1 da kapsayan üretim alanlarında küresel olarak yayılmıştır (Hanson ve ark.,2010; Hashem ve Abo-Elyousr, 2011). Kök-ur nematodları yaşamlarının bir kısmını toprakta yumurta veya II. dönem larva (J2) olarak geçirirler. İkinci dönem larva köklere girer ve uygun beslenme konumunu aldıktan sonra köklerde urlar (galler) oluşturur. Bu durum bitkinin topraktan yeterince su ve besin maddesi alımını engelleme yolu ile bitkide verim ve kalite düşüşlerine neden olurlar (Echeverrigaray ve ark., 2010).

Kök-ur nematodları (Meloidogyne spp.) bitki yetiștiriciliğinin yapıldı $\breve{g}_{1}$ tropik, subtropik ve 1 lıman bölgelerde yetiştirilen ürünlerin çoğunda büyük ve ciddi tehdit oluşturmaktadır (Moens ve ark., 2009). Bu nematodların en zararlı türü olan Meloidogyne incognita özellikle gelişmekte olan ülkelerde sebze üreticiliğinin yapıldığı alanlarda yüksek seviyelerde bulaşık olduğu bilinmektedir (Khan ve ark., 2000).Türkiye'de $M$. incognita, $M$. arenaria, M. javanica ve M. hapla'nın kök ur nematod türlerinin en yaygın türler olduğu ve bunlar içerisinde en fazla yayılım gösteren türün $M$. incognita olduğu rapor edilmiştir (Kepenekci, 2012).

Bitki paraziti Nematodlarla mücadelele çoğunlukla dayanıklı çeşitlerin kullanılması, ürün rotasyonu, kültürel ve kimyasal mücadele olarak yapılmaktadır (Chitwood, 2002). Sentetik kimyasalların kullanımı çoğunlukla pahalı ve hedefte olmayan faydalı popülasyonlara risk oluşturmaktadır. Nematod kontrolünde önemli olan kimyasallardan biri olan Methyl Bromid (MeBr)'in yoğun olarak kullanılması ile çevreye ve insan sağlığına olan zararları yaygın bir şekilde rapor edilmiştir. Bu sebepten dolayı bu ve buna benzer kimyasalların bir çok ülkede kullanımı sınırlandırmış veya tamamen yasaklamıştır (Moens ve ark., 2009). Nematod mücadelesinde ekim öncesi toprak fümigasyonu uygulamalarında kullanılan Methyl Bromide (MeBr) ve benzeri kimyasalların stratosfer tabakasına olan zararından dolayı 2005'den itibaren 
Türkiye dahil gelişmekte olan ülkelerin tamamen yasaklanmıștır (UNEP, 2006). Nematod ile mücadele yönetiminde etkili bir yöntem olan MB'nin kullanımının durdurulmasıyla birlikte araştırıcılar çevreye uygun ve hızlı sonuç alınabilen kimyasallara alternatif mücadele yöntemleri arayışına girmişlerdir (Qiao ve ark., 2014). $\mathrm{Bu}$ alternatiflerden bir tanesi de biyolojik mücadele olup biyolojik kontrol ajanları veya nematod antagonist bitkilerinin kullanılması hız kazanmıștır (Sharon ve ark., 2001; (Chitwood, 2002; Akhtar, 2004;Khattak, 2008). $\mathrm{Bu}$ sebepten dolayı, yapılan çalışmalarda nematod popülasyonlarını baskılayıcı etkiye ve özelliğe sahip bitki kökenli ekstraktları, kök salgıları, bitki uçucu yağları vb. gibi doğal maddeler tespit edilmiștir Lamiaceae, Asteraceae, Myrtaceae, Rutaceae, Lauraceae dahil toplam 57 familyaya ait bir çok bitkide nematisit etkiye sahip bileşenler bulunmuştur (Sukul, 1992; Andres et al., 2012).

Hiyar (Cucumissativus L.) ve domates (Solanum lycopersicum L.) dünyadaki önemli sebzelerin başında gelmektedir. Hıyarın dünyadaki üretimi 71,365 bin ton (FAO, 2013), ülkemizdeki üretimi 1,845 bin ton civarında (TUIK, 2015)'dır. Domatesin dünyadaki üretimi ise 163,963 bin ton (FAO, 2013), ülkemizdeki üretimi ise 11,850 bin ton (TUIK, 2015) dur. Mevcut çalışmada Arthrobacter (ROA) ve Kadife Çiçeği (Tagetes patula) ekstraktlarının yaygın ve önemli olan kök-ur nematodu, Meloidogyne incognita (Kofoid \& White)'ya karşı etkinliğinin belirlenmesi amaçlanmıştır.

\section{MATERYAL ve METOT}

\section{Nematodların Elde Edilmesi ve Çoğaltılması}

Denemede kullanılan kök-ur nematodları Kahramanmaraş ili ve çevresinde yetiştirilmekte olan nematod ile bulaşık sebze alanlarından daha önce elde edilmiş olup, bitki büyüme odasında tek yumurta paketinden çoğaltılmıştır. Tek yumurta paketinden çoğaltılmış dişilerin teşhisleri Polyacralamide Gel Eloctrophoresis (PAGE) ve Perinneal kesit yöntemleri ile yapild1ktan sonra nematoda hassas Safir domates çeşidi üzerinde 2 ay boyunca çoğaltılarak mevcut deneme için istenilen yumurta veya 2 . dönem (J2) larvalar sayıları elde edilmiştir. Çalışmada ihtiyaç duyulan nematodların ekstraksiyonu $0.25 \%$ Sodium Hypochlorite solüsyonun kullanıldığı Hussey ve Barker (1973) tekniğinin Bonetti and Ferraz (1981) tarafindan modifiye edilmiş yöntemi ile elde edilmiştir.

\section{Saksıların Hazırlanması ve Nematodların Bulaştırılması \\ Viyollerde hazır olarak alınan (Anamas Tohum,} Antalya) 4 haftalı Hiyar (Cucumis sativus L.) Yakamoz ve Domates (Solanum lycopersicum L.) Safir çeşidi fideler $\% 60$ kum \%30 toprak ve $\% 10$ da torfdan oluşan karışımla doldurulmuş, 5 L'lik (25 cm çapında) plastik saksılara şaşırtılmıştır. Dikimden 7 gün sonra (23 Eylül 2011), çoğaltma amaçlı yetiştirdiğimiz domates bitki köklerinden elde edilen yumurta ve 2. dönem larva (J2)'ların sayımları yapıldıktan sonra, her bir bitkinin kök boğazından $2 \mathrm{~cm}$ uzaklıkta ve $2 \mathrm{~cm}$ derinlikte karşılıklı açılan 4 adet çukura istenilen seviyelerde nematod bulaştırılması yapılmıştır. Nematodların bulaştırıldığı çukurlar dikkatli bir şekilde yine aynı karışım ile kapatılmış ve saksılar hafif bir şekilde sulanmıştır. Bitkiler ihtiyaç duyulduğunda sulama, gübreleme, koltuk alma, ipe sarma, vs. gibi bakımları periyodik bir şekilde yapılmıştır.

\section{Deneme Deseni}

Deneme Kahramanmaraş Sütçü İmam Üniversitesi, Avşar yerleşkesi'nde bulunan Ziraat Fakültesi'ne ait cam seralarda, 2011-2012 y1lları arasında yürütülmüştür. Deneme $2 \times 4 \times 3 \times 5$ tesadüfî bloklar deneme desenine göre tasarlanmıştır. Mevcut çalışmada Yakamoz (Hıyar) ve Safir (Domates) çeşitleri üzerinde, 3 farklı muamele (Tagates patula, Arthrobacter, İprodione) (Tablo1) ve bir kontrol (uygulamasız) ve üç farklı ikinci dönem larva (J2) nematod inokulum seviyesi [nematodsuz (0 J2 nematod/saks1), düşük (1000 $\mathrm{J} 2$ nematod/saks1) ve yüksek (2000 J2 nematod/saks1)] parametrelerinden oluşmuş olup, her bir bitki için 60, toplamda 120 saksı ile yürütülmüştür.

Tablo 1. Denemede kullanılan muameleler

\begin{tabular}{ll}
\hline Muamele & Bilimsel İsim veya Etken Madde \\
\hline Kadife Çiçeği & Tagatespatula \\
ROA & Arthrobacter \\
Devguard 500SC (Nematisit) & İprodione \\
\hline
\end{tabular}

\section{Muamelelerin Uygulanması}

\section{a. Tagetes patula muamelesi}

Topraktan taze olarak sökülen çiçeğe binmiş ortalama yaş ağırlığı $200 \mathrm{~g}$ olan 4 adet (toplamda $800 \mathrm{~g}$ ) kadife çiçeği (Tagetes patula) mevcut Allelopathic bileşiklerin elde edilmesi için 10 gün boyunca $80 \mathrm{~L}$ suda bekletilmiştir. Bitki materyalleri 10. günün sonunda ilgili solüsyondan arındırılmış ve yaklaşık 10 günde 1 uygulama olacak şekilde, her bir uygulama için ilgili saksı başına yaklaşık $330 \mathrm{ml}$ olarak uygulanmıştır (Tablo 2)

\section{b. Arthobacter (ROA) muamelesi}

Dört ml kapasiteli ticari tüp içinde satın alınan ROA (Arthrobacter sp., ROA922) (ROA teknolojileri, Antalya) 3 L su ile karıştırılarak seyreltildikten sonra, saksı başına $8 \times 10^{6}$ koloni oluşturabilecek bakteri 
gelecek şekilde (150 ml solüsyon/saksı ), 15 günde bir olmak üzere ilgili saksılardaki bitkilere uygulanmıștır (Tablo 2).

\section{c. İprodione (Devguard) muamelesi}

Diğer muamelelerle karşılaştırılmak üzere denemede Devguard [(İprodione)3-(3,5-dichlorophenyl)-Nisopropyl-2,4-dioxoimidazolidine-1-carboxamide)]
(Doğal Kimyevi Maddeler ve Zirai İlaçlar A.S., İstanbul) nematisiti kullanılmışır. $\mathrm{Bu}$ nematisitin $500 \mu$ m'lik miktarı yaklaşık $3 \mathrm{~L}$ su ile karıştırıldıktan sonra, saksı başına $150 \mathrm{ml}$ solüsyon gelecek şekilde 15 günde bir olmak üzere ilgili saksılara uygulanmıștır (Tablo 2).

Tablo 2. Denemede kullanılan muamelelerin uygulanıș tarihleri.

\begin{tabular}{clcc}
\hline Muamele & Tagates patula & Arthrobacter & İprodione \\
\hline I & 30 Eylül 2011 & 19 Eylül 2011 & 20 Eylül 2011 \\
II & 10 Ekim 2011 & 04 Ekim 2011 & 18 Ekim 2011 \\
III & 20 Ekim 2011 & 19 Ekim 2011 & 01 Kasım 2011 \\
IV & 10 Kasım 2011 & 03 Kasım 2011 & 15 Kasım 2011 \\
V & 21 Kasım 2011 & 18 Kasım 2011 & 29 Kasım 2011 \\
VI & 30 Kasım 2011 & 30 Kasım 2011 & 14 Aralık 2011 \\
VII & 09 Aralı 2011 & 15 Aralı 2011 & 30 Aralık 2011 \\
IX & 19 Aralk 2011 & 30 Aralı 2011 & $*_{-}$ \\
X & 29 Aralı 2011 & $*_{-}$ & $*_{-}$ \\
\hline
\end{tabular}

*Uygulama yapılmamıştır.

Deneme boyunca iki haftada bir bitki boy uzunlukları kaydedilmiştir. Nematodların bulaștırılmas ve muamelelerin uygulanmasından yaklaşık 90 gün sonra bitkiler kök boğazı seviyesinden kesilerek hasatları yapılmıştır. Her bir bitkinin kökleri yıkanarak topraklarından arındırıldıktan sonra 0-5 skalasına göre köklerde oluşan ur indeksi hesaplanmıştır $(0=$ ur yok, 1 $=1-2,2=3-10,3=11-30,4=31-100$ ve $5=>100$ ) (Taylor ve Sasser, 1978). Ayrica hasattan hemen sonra bitkilerin yaş ağırlıkları gram cinsinden kayıt altına alınmıştır.

\section{İstatistik Analizler}

Elde edilen veriler ANOVA varyans analizi SPSS versiyon 21 programı yardımı ile hesaplanmıș olup, veri ortalamaları Duncan Çoklu Karşılaştırma testi ile karşılaştırılarak farklar ortaya konulmuştur.

\section{BULGULAR ve TARTISMA}

Domates bitki boy ortalamalarının muameleler ve nematod seviyelerine göre farklılık göstermesine rağmen, nematod inokulasyon seviyelerinin tamamında III. ölçümlerinin diğer uygulamaların aynı ölçümün bitki boy ortalamalarından belirgin bir şekilde yüksek olduğu gözlemlenmiştir (Tablo 3). Hiyar bitki boy ortalamalarının da muameleler ve nematod seviyelerine göre farklılıklar gösterdiği ve yüksek bitki boy ölçümlerinin genelde karşılaştırma amaçlı kullanılan Iprodione uygulamalarında ortaya çıktığı görülmüştür (Tablo 4). Bitki yaş ağırlığının hem domates hem de hıyar bitkilerinde tüm nematod seviyelerinde ve tüm muameleler arasinda nematodlu kontrol parsellerine göre yüksek bulunmasına rağmen en yüksek değerler karşılaştırma amaçlı kullanılan Iprodine muamelesinde görülmüştür (Tablo 5, 6). Domates bitkisinde muameleler arasında oluşan gal indeksi değerleri karşılaştırıldığında Tagetes patula'nın (1000 J2/saks1 nematod seviyesinde 1.0 ve $2000 \mathrm{~J} 2$ / saks1 seviyesin de ise 2.4) ROA Arthobacter (1000 J2/saks1 nematod seviyesinde 1.8 ve $2000 \mathrm{~J} 2 /$ saks1 seviyesin de ise 3.4) ile kontrol (Nematodlu, uygulamasiz) (1000 J2/saks1 nematod seviyesinde 3.8 ve $2000 \mathrm{~J} 2 /$ saks1 seviyesin de ise 4.8) muamelelerine göre belirgin bir şekilde düşük bulunmuştur (Tablo 5). Hiyar bitkisinde ise özellikle $2000 \mathrm{~J} 2 /$ saksı nematod seviyesinde yine kadife çiçeğinin (2.2 gal indeksi) yaklaşık olarak kontrol amaçlı kullanılan Iprodine kimyasalı kadar (2.0 gal indeksi) düşük gal oluşumuna sebep verdiği görülmüştür (Tablo 6). Çalışmamızda elde edilen sonuçları destekleyen birçok çalışma mevcuttur. Örneğin, El Allagui ve ark. (2007) yaptıkları çalışmalarda kadife çiçeğinin kök-ur nematodu türlerine karşı \%82 ile \%84 gibi yüksek nematisit etkiye sahip olduğunu bulmuşlardır. Aynı çalışmada yapılan analizlerde bu bitki ekstraktının nematisit özelliğinin yüksek oranda flavonoid içeriğinden kaynaklandığı saptanmıştır. Çalışmamızla paralellik gösteren bir başka çalışmada, Tagetes erecta ve T. Patula thohumlarından alınan ekstaraktların Heterodera schachtii, Meloidogyne hapla ve Pratylenchus penetrans gibi bitki parasiti nematodlarına karş1 belirgin bir şekilde etkili olduğu görülmüştür (Riga ve ark., 2005). Ancak, Marahatta ve ark., (2012) tarafından yapılan bir çalışmada Tagetes patula'nın Meloidogyne türlerine karşı etkisinin değişken olduğu bildirilmiştir. Aynı çalışmada torağa sürekli ve aktif haldeki kadife çiçeğinin kök ur nematodlarına karşı daha etkili olduğu bildirilmektedir (Marahatta ve ark., 2012). 
KSÜ Doğa Bil. Derg., 19(2), 221-226, 2016

Tablo 3. Domates bitkisinde kök-ur nematodu (Meloidogyne incognita)'nın üç ayrı inokulasyon seviyesi (0, 1000, ve $2000 \mathrm{~J} 2 / \mathrm{saks1}$ )'inde ölçülen bitki boy ortalama uzunluklarının (cm) muameleler arasında karşılaştırılması.

\begin{tabular}{|c|c|c|c|c|}
\hline Muameleler & I. ölçüm & 0J2 $\frac{\text { II. ölccüm }}{\text { nematod/saks1 }}$ & III. ölçüm & IV. ölçüm \\
\hline Tagetes patula & $16.0 \mathrm{a}$ & $45.0 \mathrm{~b}$ & $94.0 \mathrm{a}$ & $140.2 \mathrm{c}$ \\
\hline ROA Arthrobacter & $14.0 \mathrm{~b}$ & $47.0 \mathrm{ab}$ & $92.0 \mathrm{ab}$ & $138.0 \mathrm{c}$ \\
\hline İprodione & $11.0 \mathrm{c}$ & $48.5 \mathrm{a}$ & $93.0 \mathrm{ab}$ & $146.0 \mathrm{~b}$ \\
\hline Kontrol (uygulamasız) & $14.0 \mathrm{~b}$ & $\begin{array}{c}48.0 \mathrm{a} \\
1000 \mathrm{~J} 2 \text { nematot/saks1 }\end{array}$ & $90.5 b$ & $151.5 \mathrm{a}$ \\
\hline Tagetes patula & $15.5 \mathrm{a}$ & $35.4 \mathrm{ab}$ & $81.8 \mathrm{a}$ & $125.6 \mathrm{ab}$ \\
\hline ROA Arthrobacter & $11.6 \mathrm{~b}$ & $39.4 \mathrm{a}$ & $74.0 \mathrm{~b}$ & $123.0 \mathrm{ab}$ \\
\hline İprodione & $13.0 \mathrm{ab}$ & $30.8 \mathrm{~b}$ & $79.0 \mathrm{ab}$ & $136.5 \mathrm{a}$ \\
\hline Kontrol (uygulamasız) & $11.0 \mathrm{~b}$ & $\begin{array}{l}31.0 \mathrm{~b} \\
2000 \mathrm{~J} 2 \mathrm{nematod} / \mathrm{saks} 1\end{array}$ & $74.5 \mathrm{~b}$ & $118.5 \mathrm{~b}$ \\
\hline Tagetes patula & $14.5 \mathrm{ab}$ & $45.4 \mathrm{a}$ & $89.8 \mathrm{a}$ & $130.6 b$ \\
\hline ROA Arthrobacter & $13.2 \mathrm{~b}$ & $39.0 b$ & $86.4 \mathrm{ab}$ & $129.6 b$ \\
\hline İprodione & $15.2 \mathrm{a}$ & $45.0 \mathrm{a}$ & $84.8 \mathrm{~b}$ & $136.6 \mathrm{a}$ \\
\hline Kontrol (uygulamasız) & $12.0 \mathrm{c}$ & $30.0 \mathrm{c}$ & $70.0 \mathrm{c}$ & 120.0 \\
\hline
\end{tabular}

Aynı sütundaki farklı harfler, aynı nematod seviyesinde, Duncan Çoklu Karşılaştırma Testi’ne göre birbirinden farklıdır $(P \leq 0.05)$

Tablo 4. Hıyar bitkisinde kök-ur nematodu (Meloidogyne incognita)'nın üç ayrı inokulasyon seviyesi (0, 1000, ve $2000 \mathrm{~J} 2 / \mathrm{saks1}$ )'inde ölçülen bitki boy ortalama uzunluklarının $(\mathrm{cm})$ muameleler arasında karşılaştırılması.

\begin{tabular}{|c|c|c|c|c|}
\hline Muameleler & I. ölçüm & II. ölçüm & III. ölçüm & IV.ölçüm \\
\hline \multicolumn{5}{|c|}{$0 \mathrm{~J} 2 \mathrm{nem}$ atod/saks1 } \\
\hline Tagetes patula & $10.7 \mathrm{ab}$ & $22.0 \mathrm{~b}$ & $35.2 \mathrm{c}$ & $82.0 \mathrm{~b}$ \\
\hline ROA Arthrobacter & $10.8 \mathrm{ab}$ & $23.5 \mathrm{a}$ & $38.5 \mathrm{~b}$ & $83.0 \mathrm{ab}$ \\
\hline İprodione & $10.5 \mathrm{~b}$ & $22.5 \mathrm{ab}$ & $39.0 \mathrm{~b}$ & $83.5 \mathrm{a}$ \\
\hline Kontrol (uygulamasız) & $11.5 \mathrm{a}$ & $23.0 \mathrm{ab}$ & $40.5 \mathrm{a}$ & $83.0 \mathrm{ab}$ \\
\hline \multicolumn{5}{|c|}{$1000 \mathrm{~J} 2$ nematod/saks1 } \\
\hline Tagetes patula & $10.5 \mathrm{ab}$ & $15.8 \mathrm{~b}$ & $37.2 \mathrm{~b}$ & $72.4 \mathrm{~b}$ \\
\hline ROA Arthrobacter & $10.8 \mathrm{a}$ & $15.6 \mathrm{~b}$ & $37.6 \mathrm{~b}$ & $72.6 \mathrm{~b}$ \\
\hline İprodione & $10.4 \mathrm{ab}$ & $17.0 \mathrm{a}$ & $45.0 \mathrm{a}$ & $79.0 \mathrm{a}$ \\
\hline Kontrol (uygulamasız) & $9.7 \mathrm{~b}$ & $14.4 \mathrm{c}$ & $36.0 \mathrm{c}$ & $65.5 \mathrm{c}$ \\
\hline \multicolumn{5}{|c|}{$2000 \mathrm{~J} 2 \mathrm{nematod} / \mathrm{saks} 1$} \\
\hline Tagetes patula & $8.6 \mathrm{~b}$ & $15.4 \mathrm{bc}$ & $41.8 \mathrm{ab}$ & $74.0 \mathrm{ab}$ \\
\hline ROA Arthrobacter & $10.2 \mathrm{a}$ & $17.6 \mathrm{~b}$ & $39.4 \mathrm{~b}$ & $72.8 \mathrm{~b}$ \\
\hline İprodione & $10.0 \mathrm{a}$ & $21.0 \mathrm{a}$ & $44.0 \mathrm{a}$ & $77.0 \mathrm{a}$ \\
\hline Kontrol (uygulamasız) & $8.5 \mathrm{~b}$ & $14.0 \mathrm{c}$ & $34.4 \mathrm{c}$ & $65.0 \mathrm{c}$ \\
\hline
\end{tabular}

Aynı sütundaki farklı harfler, aynı nematod seviyesinde Duncan Çoklu Karşılaştırma Testi’ne göre birbirinden farklıdır $(P \leq 0.05)$ 
Tablo 5. Domates bitkisinde kök-ur nematodu (Meloidogyne incognita)'nın üç ayrı inokulasyon seviyesi $(0,1000$, ve $2000 \mathrm{~J} 2 / \mathrm{saks} 1$ )'inde ölçülen bitki yaş ağırlığı ve gal (ur) indeksinin muameleler arasında karşılaştırılması

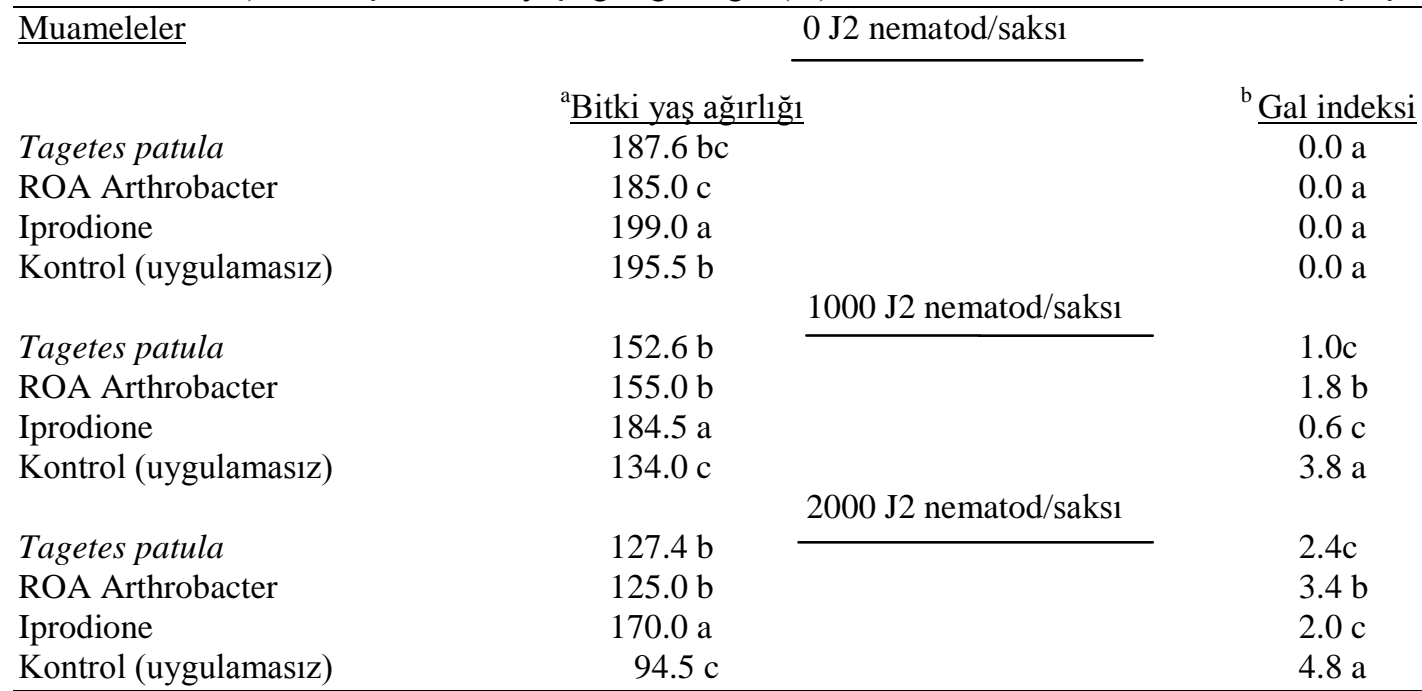

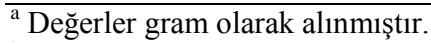

${ }^{\mathrm{b}}$ Köklerde oluşan urlanma 0-5 indeksine göre hesaplanmıştır $(0=$ ur yok, $1=1-2,2=3-10,3=11-30,4=31-100$ ve $5=>100)$ (Taylor ve Sasser, 1978).

Aynı sütundaki farklı harfler, aynı nematod seviyesinde, Duncan Çoklu Karşılaştırma Testi'ne göre birbirinden farklıdır $(P \leq 0.05)$.

Tablo 6. Hiyar bitkisinde kök-ur nematodu (Meloidogyne incognita)'nın üç ayrı inokulasyon seviyesi $(0,1000$, ve 2000 J2/saks1)'inde ölçülen bitki yaș ağırlığı ve gal (ur) indeksinin muameleler arasında karşılaştırılması

\begin{tabular}{|c|c|c|c|}
\hline \multirow[t]{2}{*}{ Muameleler } & & $0 \mathrm{~J} 2$ nematod/saks1 & \multirow[b]{2}{*}{${ }^{\mathrm{b}}$ Gal indeksi } \\
\hline & \multicolumn{2}{|l|}{${ }^{\text {a} B i t k i ~ y a s ̦ ~ a g ̆ ı r l ı g ̆ ~}$} & \\
\hline Tagetes patula & $189.6 \mathrm{ab}$ & & $0.0 \mathrm{a}$ \\
\hline ROA Arthrobacter & $185.0 \mathrm{~b}$ & & $0.0 \mathrm{a}$ \\
\hline Iprodione & $201.0 \mathrm{a}$ & & $0.0 \mathrm{a}$ \\
\hline \multirow[t]{2}{*}{ Kontrol (uygulamasız) } & $202.2 \mathrm{a}$ & & $0.0 \mathrm{a}$ \\
\hline & & $1000 \mathrm{~J} 2$ nematod/saks1 & \\
\hline Tagetes patula & $152.8 \mathrm{~b}$ & & $2.0 \mathrm{~b}$ \\
\hline ROA Arthrobacter & $153.8 \mathrm{~b}$ & & $1.8 \mathrm{~b}$ \\
\hline Iprodione & $185.2 \mathrm{a}$ & & $0.6 \mathrm{c}$ \\
\hline \multirow[t]{2}{*}{ Kontrol (uygulamasız) } & $136.4 \mathrm{c}$ & & $2.9 \mathrm{a}$ \\
\hline & & $2000 \mathrm{~J} 2$ nematod/saks1 & \\
\hline Tagetes patula & $127.2 \mathrm{~b}$ & & $2.2 \mathrm{c}$ \\
\hline ROA Arthrobacter & $124.4 \mathrm{~b}$ & & $3.4 \mathrm{~b}$ \\
\hline Iprodione & $182.6 \mathrm{a}$ & & $2.0 \mathrm{c}$ \\
\hline Kontrol (uygulamasız) & $105.2 \mathrm{c}$ & & $4.4 \mathrm{a}$ \\
\hline
\end{tabular}

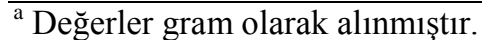

${ }^{\mathrm{b}}$ Köklerde oluşan urlanma 0-5 indeksine göre hesaplanmıştır $(0=$ ur yok, $1=1-2,2=3-10,3=11-30,4=31-100$ ve $5=>100)$ (Taylor ve Sasser, 1978).

Aynı sütundaki farklı harfler, aynı nematod seviyesinde, Duncan Çoklu Karşılaştırma Testi'ne göre birbirinden farklıdır $(P \leq 0.05)$

\section{SONUC}

$\mathrm{Bu}$ çalışmada iki farklı bitki türüne üç farklı nematod inokulum seviyesinde üç farklı uygulamada bulunulmuş ve yüksek verim kayıplarına neden olan Meloidogyne incognita ile mücadelede alternatif savaşım yöntemleri aranmıştır. Bitki boyu, kök urlanma miktarı ve yaş ağırlık parametreleri karşılaştırıldığı zaman İprodione etken maddeye sahip nematisitin bitki yaş ağırlığına etkisinin en yüksek olduğu görülmüştür. Tagete spatula ve ROA (Arthrobacter) uygulamalarının her iki inokulum seviyesindeki sonuçları kontrol + ile istatistiki olarak karşılaştırıldığı sonuçlar önemli derecede farklı ve etkili bulunmuştur.

$\mathrm{Bu}$ çalıșmadan elde edilen sonuçlar göz önüne alındığında Tagetes patula ve ROA (arthrobacter) uygulamalarının düşük maliyet içermesi ve kolay 
uygulanabilirliği açısından Meloidogyne incognita ile mücadelede özellikle sera domates ve hiyar üretimlerinde kullanılabileceği görülmüştür.

Tarımın sürdürülebilirliğine katkıda bulunma amaçlı ve bitkisel üretimi maksimize etmek için dünya çapında uygulanan zararlı yönetimi alternatiflerin arayışı her gün hız kazanırken, özellikle botanik kökenli doğal nematisitlerin önemi artmaktadır. $\mathrm{Bu}$ bağlamda, özellikle kadife çiçeği (Tagetes patula) bitki ekstraktının tek başına nematod mücadelesinde kullanılabileceği ayrica IPM (Intregated Pest Management) nematod yönetiminde de rahatlıkla yer alabileceği düşünülmektedir.

\section{KAYNAKLAR}

Andres, M. F., Coloma, A. G., Sanz, J., Burillo, J., Sainz, P., 2012. Nematicidal activity of essential oils: a review. Phytochem. Rev. DOI 10.1007/s11101-012-9263-3.

Akhtar, M., 2004. Current options in integrated management of plant-parasitic nematodes. Integrated Pest Management Review, 2: 187-197.

Bonetti, J. I. S., Ferraz, S., 1981. Modificações do método deHussey and Barker para a extração de ovos de Meloidogyne exigua, em raízes de cafeeiro K. Fitopatologia Brasileira, 3:553.

Chitwood, D. J., 2002. Phytochemical based strategies for nematode control. Annual Review of Phytopathology, 40: 221-249.

Echeverrigaray, S., Zacaria, J. Beltrão, R., 2010. Nematicidalactivity of monoter-penoids against the root-knot nematode Meloidogyne incognita. Phytopathology, 100: 199-203.

El Allagui, N., Tahrouch, S. Bourijate, M. Hatimi, A., 2007. Action of plant extracts on rot-knot nematodes (Meloidogyne ssp.) mortality [Action de différents extraits végétaux sur la mortalitédes nématodes à galles du genre Meloidogyne ssp.]. Acta Botanica Gallica,. 154: 503- 509.

Hanson, B. D., Gerik, J.S. Schneider, S. M., 2010. Effects of reduced-rate Methyl bromide applications under conventional and virtually impermeable plastic film in perennial crop field nurseries. Pest Management Science, 66: 892-899.

Hashem, M., Abo-Elyousr, A. K., 2011. Management of the root-knot nematode Meloidogyne incognita on tomato with combinations of different biocontrol organisms. Crop Protection, 30 (3): 285-292.

Hussey R.S., Barker, K. R., 1973. A comparison of methods for collecting inocula of Meloidogyne spp. including a new technique. Plant Disease Reporter. 57: $1025-1028$.
Kepenekci, I., 2012. Nematoloji (Bitki Paraziti ve Entomopatojen Nematodlar) [Genel Nematoloji (Cilt-I) ISBN 978-605-4672-11-0, Taksonomik Nematoloji (Cilt-II) ISBN 978-605-4672-12-7] [Nematology (Plant parasitic and Entomopathogenic nematodes) (General Nematology, Volume-I) (Taxonomic Nematology, Volume-II) pp.1155.] Eğitim, Yayım ve Yayımlar Dairesi Başkanlığı, Tarım Bilim Serisi Yayın No:3 (2012/3), LIV+1155.

Khan, H., Ahmad, R., Akhtar, A. S., Arshad, M., Tahir, B., Tariq, N., 2000. Effect of inoculums density of Meloidogyne incognita and plantage on the severity of root knot disease in tomato. International Journal of Agricultural Biology, 2: 360-363.

Khattak, B., 2008. Biological management of root knot Nematode Meloidogyne javanica (Treub) with Trichoderma harzianum Rifai in Tomato. Dissertation. The University of Agriculture, Peshawar.

Marahatta, P. S., Wang, K. H., Sipes, B. S., .Hooks, C. R. R., 2012. Effects of Tagetes patula on active and inactive stages of root-knot nematodes. Journal of Nematology, 44 (1): 26-30

Moens, M., Perry R. N., Starr, J. L., 2009. Meloidogyne species: a diverse group of novel and important plant parasites. In: Perry, R. N., Moens, M., Starr, J. L. (Eds.), Root-knot Nematodes. CABI, Wallingford, pp. 1-13.

Riga, E., Potter, J., Hooper, C., 2005. In vitro effect of marigold seed exudates on plant parasitic nematodes. Phytoprotection, 86: 31-35.

Roa Biyoteknoloji, http://www.roabiyoteknoloji.com.

Qiao, K., Duan, H., Wang, H., Wang, Y., Wang K., Wei, M., 2014. The efficacy of the reducedrates of 1,3-D + abamectin for control of Meloidogyne incognita in tomato production in China. Scientia Horticulturae, 178: 248-252.

Sharon, E., Bar-Eyal, M., Chet, I., Herrera-Estrella, A., Kleifeld, O., Spiegel, Y., 2001. Biological control of the root-knot nematode Meloidogyne javanica by Trichoderma harzianum. Phytopathology, 91: 687693.

Sukul, N. C., 1992. Plant antagonist to plant-parasitic nematodes. Indian Review of Life Sciences, 12: 23 52.

Taylor, A. I., Sasser, J. N. 1978. Biology, identification and control of root-knot nematode (Meloidogynesp.) North Carolina State University Graphics, Raleigh. NC 27607

UNEP (United Nations Environment Programme Ozone Secretari), 2006. The Montreal protocol on substances that deplete the ozone layer, seventh ed. UNEP, Available at: http://ozone.unep.org/ Publications/MP Handbook (accessed 22.09.10). 